\title{
Influence of Social Cultural Factors on Management of Resources in Awoja Watershed
}

\author{
Charles Aben" ${ }^{\circledR}{ }^{\circledR}$, John James Okiror ${ }^{1}$, Jacob Godfrey Agea ${ }^{1}$, Esbern Friis Hansen ${ }^{2}$ \\ ${ }^{1}$ Department of Extension and Innovation Studies, College of Agricultural and Environmental Sciences, Makerere University, \\ Kampala, Uganda \\ ${ }^{2}$ Danish Institute for International Studies, Copenhagen, Denmark \\ Email: charlesaben@gmail.com
}

How to cite this paper: Aben, C., Okiror, J.J., Agea, J.G. and Hansen, E.F. (2019) Influence of Social Cultural Factors on Management of Resources in Awoja Watershed. American Journal of Climate Change, 8, 343-363.

https://doi.org/10.4236/ajcc.2019.83019

Received: May 7, 2019

Accepted: August 16, 2019

Published: August 19, 2019

Copyright (c) 2019 by author(s) and Scientific Research Publishing Inc. This work is licensed under the Creative Commons Attribution International License (CC BY 4.0).

http://creativecommons.org/licenses/by/4.0/

\begin{abstract}
The influence of social institutions in the management of control of access to watershed resources in a changing climate has not been fully explored. This study examined the influence of social factor variables on the management of control of access to Awoja watershed. The study was conducted in Awoja watershed in Eastern Uganda facing frequent floods and draughts. The study used a cross sectional research design involving factor analysis and logistical regression to determine the influence of social contextual factors on watershed management. Qualitative methods were also used to explain statistical trends. From the household survey data correlation results indicated that, there was a significant relationship between the social issues and management of the watershed $(\mathrm{r}=0.353, \mathrm{P}<0.01)$. The results however indicated a negative relationship between social issues and climate change factor $(r=-0.489$, $\mathrm{P}<0.01)$. This means that as climate change increases, the ability to control access to watershed resources decreases. From the factor analysis results five factors were significantly correlated to the control of access: declining cohesion $(\mathrm{r}=0.273, \mathrm{P}<0.01)$, contribution of social organizations $(\mathrm{r}=0.417, \mathrm{P}<$ $0.001)$, rationale for access $(\mathrm{r}=0.203, \mathrm{P}<0.01)$, community involvement $(\mathrm{r}=$ $0.560, \mathrm{P}<0.001)$ and interventions in watershed utilization $(\mathrm{r}=-0.249, \mathrm{P}<$ 0.01 ). From the Logistical Regression two factors "institutions" and "rationale for access" had an increasing influence on watershed management while the other factors had a decreasing influence on watershed management. However, while the influence of institutions was increasing and significant, the influence of rationale for access to protected areas was increasing but not significant. Factors with negative influences included culture, social cohesion and social conflicts which had significant negative influence. The study also found that climate change had negative consequences on existing social institutions due to its ability to erode the powers of traditional institutions and to intensify resource conflicts. The study recommended the need for a local
\end{abstract}


governance system to empower the key gatekeepers in the watershed management in order to promote the role of social institutions in the control of access to watershed resources.

\section{Keywords}

Watershed Management, Social Cultural Interests, Climate Change Adaptation

\section{Introduction}

The interface between the social institutions and watershed management in a changing climate has been accorded little attention [1]. Climate change adaptation measures have given less attention to social and institutional alternatives for reducing vulnerability and enhancing adaptation. Climate change impacts amplify existing unfavourable conditions [2] and poor members of the community are more vulnerable [3].

The roles of social systems in water shade management have been found to be crucial and a useful framework for analyzing processes regarding land ownership, utilization and consumption in the context of wetlands management [4]. Watersheds management in the context of climate change adds a new dimension to social cultural dynamics because it uncovers the inequalities underlying management and utilization within the watersheds [5]. Social practices evolve and take on new forms over time and regulation, social codes of conduct and shared cognitions and logics legitimize various types of collective action [6]. Further, divergent practices may become embedded in team culture that the repertoires or arrangements that shape conceptions become institutionalized. Arccordingly participation of actors becomes an avenue for influencing practice 10. Similarly, the level of community participation determines the success of management of watersheds [7] [8]. However, in Uganda, despite the participation of the local community effective watershed management in Eastern Uganda has not been fully realised [9]. To date, these watersheds continue to face degradation due to over dependence on watershed resources 16, 17.

This study analysed the influence of different social factor variables on control of access to resources in Awoja watershed in Eastern Uganda. The main conviction was that unless the role of social institutions in the control of access to resources in a changing climate is well understood the sustainability of this important wetland system will remain at stake.

\section{Materials and Methods}

\subsection{The Study Area}

The study was conducted in the sub counties of Magoro, Wera and Gweri in the districts of Katakwi, Amuria and Soroti respectively in the areas bordering the 
main water bodies/swamps that constitute Awoja wetlands system. The communities of this sub-region are mainly agro-pastoralists, practicing the Teso Farming System characterized by both crop production and livestock rearing. These areas suffer from similar incidents of flooding, draughts and displacements but, vary widely in their water and land resource endowments and utilization. They also differ in the extent of implementing of natural resource laws and regulations. The sub-region experiences bi-modal type of rainfall and crop production is by far rain-fed. The crop production cycle follows the pattern of rainfall on annual basis. The average rainfall is $1200 \mathrm{~mm}$ per annum. The vegetation of the sub-region can best be described as grassland-savanna predominated by grassland and shrubs. The soils are mainly sandy loam with variation from sandy to loamy soils depending on the terrain.

\subsubsection{Research Design}

The study applied a cross sectional survey research design. This design together with the quantitative and qualitative data collection and analysis methods allowed triangulation; which is viable in generating quality results [10]. The qualitative and quantitative approaches generated information on watershed management and the complex interrelationships between social and ecological environment.

\subsubsection{The Study Population}

The main target was the households within the watershed and the local governance institutions: formal and informal; in Awoja watershed, particularly those involved in the implementation of climate change adaptation activities. Resource user communities in the areas adjacent to the wetlands systems that constitute the Awoja basin were directly targeted. Local council committee members were also involved in the study.

\subsubsection{Samplesize and Sample Selection}

Systematic random sampling (involving randomly selecting the first household at random with the subsequent households selected at an interval) was used to select a total of 180 household respondents. The sampling method was used to select 32 household respondents in Omugenya, Village while 28 were selected in Omusia village in Gweri Sub County. In Magoro Sub County, Angisa Parish was selected and two villages; Apopong village was selected from which 31 households were selected. The other village; Angaro was also selected and 29 households were selected to participate in the study. In Amuria; Wera Sub County was selected from which two villages were selected in Wera Parish. These villages are Morungatuny from which 30 households were selected and Okile Villages where 30 households were selected. This made a total of 180 households that participated in the study. One focus group discussion was conducted from each village comprising between 8 - 12 respondents, making a total of 6 focus groups discusions for the study. A focus group discussion should involve members ranging from 6 - 12 for adequate response [11].

Snowballing technique was used for selection of key informant interview. In 
this technique the initial informants were used to nominate others through their social networks, who could potentially contribute to the study. The respondents included local government leaders, NGO staff involved in climate change adaptation activists, and community leaders including cultural institutions. Focus Group Discussions (FGDs) were used to analyze community dynamics and provide an understanding of underlying social issues in watershed management.

\subsection{Data Collection}

\subsubsection{Review of Secondary Data Sources}

This involved a comprehensive literature review to capture information on legal, policy, administrative and implementation frameworks related to natural resource management at local government levels. It also reviewed relevant information and other studies from various sources. Some of the documents reviewed included: The National Climate Change Policy (NCCP, 2012), the Local Government Act (1997), The Decentralization Policy, Wetlands Protection Act, Development Plans, Annual Budgets, Monitoring and Evaluation Reports. Other documents reviewed include books, journal papers and other relevant document to the subject matters.

\subsubsection{Key Informants' Interviews}

This was used to collect primary data that was used to evaluate the policy development processes, including the principles in the framing of policies governing natural resource management. The tool was also used to measure variations between policy frameworks and real governance practices of natural resource management in a changing climate and influence of stakeholders on institutional practice.

Face-to-face/one-on-one interviews with civic leaders and leaders of NGOs involved in adaptation to climate change were carried out to achieve the above objectives. Semi structured questionnaires were used due to their flexibility to probe for details. Information from respondents at various levels of governance, local government technical (Sub county: Senior Assistant Secretaries, Parish Chiefs, Environment Focal Point Officers, and political wing (LC III Chairperson, Councilors, and members of the Sub-county executive) were collected. Information was also collected from CSOs and extra local institutions (members of Parish Development Committees and members of Disaster Risk Management Committees).

\subsubsection{Focus Group Discussions}

This was organized at 2 levels. First it was conducted in at least two parishes in each of the three sub counties under study in the 3 districts. Each parish level FGD had at least 8 - 12 people selected with the help of Local Government and NGO partners at the sub county. Efforts were made to cover variations among women, youth and the elderly. This was meant to measure community perceptions on local participation in resource management. It was also used to measure 
social inclusiveness of policies, and institutions governing adaptation in the study area. Secondly, FGDs were conducted at institutional levels to determine the organization profiles, institutional linkages, institutional interactions and changes in policy and practice among institutions involved in adaptation to climate change. NGOs, CBOs and Local Government partners in climate change adaptation were involved in the institutional profile study. For each institution, the participants were drawn from the two major levels of the institutions (administrative and field level).

\subsubsection{Household Survey Questionnaire}

Data from qualitative study was used to focus the design of household survey questionnaire. The aim of the questionnaire survey was firstly, to measure the influence of political, economic and social drivers on watershed management. Secondly it determined the social and economic status of communities in Awoja (livelihoods assets, education, etc). A model that allowed the prediction of how political, economic and social factors influence management decisions was generated as observed in the subsequent chapters.

\subsection{Data analysis and Interpretation}

\subsubsection{Qualitative Data Analysis}

Qualitative data was analyzed through an iterative process. Data collected was grouped to make simple inferences that allowed a link where analysis of data was not a distinct stage of the process of research but, built in from the research design and pre fieldwork phase. Analysis was also based on data themes generated from the qualitative interviews, while additional data was collected based on gaps realized during the analysis. Reflexivity was employed in order to inwardly identify meanings of relationships emerging from the data collected in the field.

\subsubsection{Quantitative Data Analysis}

For quantitative analysis, data entry template was prepared using epidata (version 3.2) from the revised questionnaire following the pilot study. Data from the respondents were organized, entered in epidata, and exported to stata software (version 13.1) for cleaning and analysis. The data was then explored for normality by using Kolmogorow-Smirnov normality test and were normally distributed $(\mathrm{P}>0.05)$, to decide on the probable statistics if relevant assumptions were met. Since the assumptions for parametric tests were met, the study utilized both descriptive and inferential statistics amenable to parametric analysis. Whereas descriptive statistics involved the use of central tendency (means), frequencies, proportions, standard deviation and variance; the inferential tests employed the use of Pearson $r$ correlation to test the relationships between the main study variables and the nature thereof; as well as to test the hypotheses. Although the bivariate relationships were examined, logistic regression analysis was performed to establish the influence of the independent variables (local political processes, economic interests, social cultural factors) on the dependent variable (management of the water shed). The study employed factor analysis to identify the in- 
dependent factors explaining relationships amongst the main variables; factor analysis was performed to establish the strength of the different factors in the model.

The specific goals of factor analysis were to provide/reduce a large number of observed variables to smaller number of factors and to provide a regression equation for an underlying process by using observed variables [12]. Factor scores can be derived such that they are nearly uncorrelated or orthogonal. Thus, using the coefficients can solve the problem for multicollinearity among the variables, which are used to estimate the management of the watershed. Factor analysis determined the number of fundamental influences underlying a domain of variables, to quantify the extent to which each variable is associated with the factors and to obtain information about their nature from observing which factors contribute to performance, on which variables. This allows numerous inter-correlated variables to be condensed into fewer dimensions, called factors.

In this study, factor analysis was performed for a set of parameters that described both the dependent variable (management of the watershed) and the independent variables (local social issues). The correlation matrix of variables was used to obtain Eigen values. In order to facilitate interpretation of factor loadings $\left(l_{i k}\right)$, VARIMAX rotation was used. Factor coefficients $\left(c_{i k}\right)$ were used to obtain factor scores for selected factor (Keskin et al., 2007). The factor number equals the number of Eigen values of the population correlation matrix that are greater than unity (Tinsley and Brown, 2000). Therefore, the factors with Eigen values $>1$ were employed in regression analysis [13].

Average values for Eigen values $>1$ for each independent factor were obtained and regressed against the dependent variable.

\section{Results and Discussions}

\subsection{Factor Analysis for Social Factors on Watershed Management}

Social factors were described by 30 questions. The factorability of these questions was examined. The Kaiser-Meyer-Olkin measure of sampling adequacy was 0.78 , which is above the commonly recommended value of 0.6. The Barlett's test of sphericity was significant $\left(\chi^{2}(435)=1945.04, \mathrm{P}<0.001\right)($ Table 2$) . \mathrm{KMO}$ and Bartlett's Test of Sphericity both indicate that the set of variables are at least adequately related for factor analysis. Factor analysis for the 30 items based on principle component analysis with Varimax (Orthogonal) rotation yielded 10 factors explaining a total of $77.8 \%$ of the variance for the entire set of social factor variables (Table 1) arising from Table 2 which indicates the factor loadings with communalities based on principle component analysis with rotated factor loadings for socio interests. Factor one explaining $10.7 \%$ of the variance was labeled "Cultural influence on access to resources" due the high factor loadings of the variables; how clan systems influence access to land resources and how traditional family status has changed. Factor two explaining $10.2 \%$ of the variance was labeled "How restriction on land has changed community cohesion" and 
Table 1. Retained factors based on principle component analysis with rotated factor loadings for socio-cultural interests.

\begin{tabular}{|c|c|c|c|c|c|}
\hline Factor & Eigen values & Variance & Difference & Proportion & Cumulative \\
\hline SS1-Cultural influences on access to land resources & 4.28679 & 3.20822 & 0.16377 & 0.1069 & 0.1069 \\
\hline SS2-Declining social cohesion & 3.45792 & 3.04445 & 0.20087 & 0.1015 & 0.2084 \\
\hline $\begin{array}{l}\text { SS3-Contributions of social organizations to the } \\
\text { management of natural resources in the watershed }\end{array}$ & 3.15668 & 2.84359 & 0.25768 & 0.0948 & 0.3032 \\
\hline SS4-Rationale for access to protected areas & 3.01520 & 2.58591 & 0.29679 & 0.0862 & 0.3894 \\
\hline SS5-Role of community involvement & 2.26427 & 2.28912 & 0.17994 & 0.0763 & 0.4657 \\
\hline SS6-Interventions in utilization of the watershed & 2.18412 & 2.10918 & 0.10450 & 0.0703 & 0.5360 \\
\hline SS7-Access to protected areas & 1.49940 & 2.00467 & 0.12616 & 0.0668 & 0.6028 \\
\hline SS8-Insitutional control of wetlands use & 1.27819 & 1.87851 & 0.10068 & 0.0626 & 0.6655 \\
\hline SS9-Social effects of degradation of the watershed & 1.17999 & 1.77783 & 0.17520 & 0.0593 & 0.7247 \\
\hline SS10-Tribal conflicts in the use of the watershed & 1.02154 & 1.60262 & . & 0.0534 & 0.7781 \\
\hline
\end{tabular}

Method: principal-component factors, Rotation: orthogonal varimax (Kaiser off).

Table 2. Factor loadings with communalities based on principle component analysis with rotated factor loadings for socio interests.

\begin{tabular}{|c|c|c|c|c|c|c|c|c|c|c|c|}
\hline Variable & Factor 1 & Factor 2 & Factor 3 & Factor 4 & Factor 5 & Factor 6 & Factor 7 & Factor 8 & Factor 9 & Factor 10 & uniqueness \\
\hline Accessfo & 0.4891 & -0.0639 & 0.4356 & -0.1778 & 0.1618 & -0.0710 & 0.4771 & -0.2934 & -0.0892 & -0.0294 & 0.1816 \\
\hline Whyfores & -0.2135 & 0.0443 & 0.0427 & 0.5105 & 0.3656 & -0.2060 & 0.0704 & 0.0780 & 0.3781 & 0.3857 & 0.2112 \\
\hline Accesswe & 0.1299 & -0.4847 & 0.3159 & 0.4327 & 0.2031 & 0.0240 & -0.0912 & 0.2225 & -0.3444 & -0.0784 & 0.2367 \\
\hline Whywetla & -0.1562 & 0.0273 & 0.1353 & 0.2499 & 0.6953 & -0.0737 & -0.0322 & 0.1912 & -0.2539 & 0.1102 & 0.2910 \\
\hline Accesssa & -0.0739 & 0.1619 & 0.1689 & 0.3738 & -0.1450 & 0.0524 & 0.6163 & -0.0601 & 0.3698 & 0.0941 & 0.2474 \\
\hline Whysand & -0.0512 & -0.0777 & 0.0137 & 0.8252 & 0.1778 & -0.0960 & 0.1253 & -0.1304 & 0.0317 & -0.1556 & 0.2114 \\
\hline Accessga & 0.0939 & -0.0416 & -0.1599 & 0.0628 & 0.0011 & -0.0771 & 0.7825 & -0.2023 & -0.1643 & 0.1117 & 0.2613 \\
\hline Whygames & 0.0014 & 0.0045 & 0.0417 & 0.8068 & 0.0819 & -0.0062 & 0.0108 & 0.0662 & -0.0443 & 0.0486 & 0.3313 \\
\hline Control & -0.1072 & 0.0973 & -0.0333 & -0.0735 & -0.0699 & -0.0080 & -0.1481 & 0.5628 & -0.1100 & -0.0948 & 0.1384 \\
\hline Clan1 & 0.8351 & -0.0959 & -0.0576 & 0.0140 & -0.2004 & 0.0728 & 0.1241 & -0.2064 & -0.0015 & 0.0483 & 0.1848 \\
\hline Traditio & 0.4463 & 0.0066 & 0.1138 & 0.2273 & -0.0712 & 0.1829 & -0.4889 & -0.2610 & 0.0616 & -0.3268 & 0.2799 \\
\hline Landema & -0.6493 & 0.0029 & -0.3564 & -0.2485 & -0.0852 & 0.2697 & 0.3756 & -0.0218 & 0.0131 & 0.0276 & 0.1672 \\
\hline Doing1 & 0.0376 & 0.6373 & -0.1080 & -0.1215 & 0.2497 & -0.3027 & 0.4240 & -0.1875 & -0.0881 & -0.0548 & 0.1863 \\
\hline Acquire1 & -0.2859 & 0.5787 & -0.4775 & -0.1376 & -0.0781 & 0.1325 & 0.1320 & -0.0353 & 0.2947 & -0.0693 & 0.2024 \\
\hline Restrict & 0.0670 & 0.7959 & 0.1269 & -0.0924 & -0.1541 & -0.1651 & 0.0991 & 0.3119 & -0.0158 & 0.1451 & 0.1581 \\
\hline Familyst & 0.8205 & 0.0648 & -0.2038 & -0.1061 & 0.0909 & -0.0847 & -0.0651 & -0.0507 & -0.0569 & -0.0848 & 0.2371 \\
\hline Foodprod & -0.0301 & -0.8289 & -0.2331 & -0.0656 & 0.1449 & -0.1085 & 0.1393 & -0.0794 & -0.0309 & 0.0282 & 0.1931 \\
\hline Whyfood & -0.4674 & 0.0192 & -0.2260 & 0.4703 & -0.1809 & -0.3316 & -0.2991 & -0.1448 & -0.0013 & -0.1525 & 0.2326 \\
\hline Social & 0.1252 & -0.0699 & -0.6803 & 0.0516 & -0.4397 & 0.2221 & -0.1442 & 0.2906 & 0.0407 & 0.1059 & 0.1532 \\
\hline Culturenorem & 0.0377 & -0.1596 & 0.0406 & -0.1737 & 0.0787 & -0.0093 & -0.0158 & 0.1128 & -0.5884 & -0.2432 & 0.5166 \\
\hline Social effects & 0.0025 & 0.0030 & 0.1387 & -0.0907 & -0.0654 & 0.0785 & -0.0867 & -0.0339 & 0.8101 & -0.0742 & 0.2917 \\
\hline
\end{tabular}




\begin{tabular}{cccccccccccccc} 
Continued & \multicolumn{10}{c}{0.0 .2781} \\
\hline Experien & -0.0770 & -0.2198 & $\mathbf{0 . 5 5 7 3}$ & -0.0783 & 0.2989 & 0.3494 & -0.0281 & 0.2498 & 0.2760 & -0.0126 & 0.2781 \\
Changes1 & -0.5962 & -0.3714 & 0.0745 & 0.1047 & -0.1955 & 0.2849 & -0.1625 & -0.2568 & -0.0010 & 0.3432 & 0.1606 \\
Tribal1 & -0.1683 & 0.0410 & -0.1071 & -0.3135 & -0.0112 & -0.0083 & 0.2826 & -0.0365 & 0.0417 & $\mathbf{0}$ \\
Manage & -0.0446 & 0.1479 & $\mathbf{0 . 8 8 9 6}$ & 0.0834 & 0.0143 & 0.1982 & -0.1156 & 0.0548 & 0.1139 & 0.0555 & 0.1058 \\
Changemg & 0.1376 & -0.1737 & 0.2120 & 0.0935 & $\mathbf{0 . 8 2 5 3}$ & 0.1218 & -0.0185 & -0.1364 & 0.0321 & -0.0076 & 0.1812 \\
Gender1 & -0.2824 & -0.0888 & 0.3433 & -0.1049 & -0.3932 & $\mathbf{0 . 4 8 4 7}$ & -0.0336 & -0.1891 & 0.2312 & 0.3602 & 0.1738 \\
Improve4 & -0.0780 & 0.0240 & 0.0556 & -0.0545 & 0.0341 & $\mathbf{0 . 8 9 3 6}$ & -0.0461 & -0.0062 & 0.0352 & -0.0563 & 0.1809 \\
Involve1 & 0.1928 & 0.1939 & 0.3975 & 0.3666 & 0.1737 & -0.0328 & -0.0535 & $\mathbf{0 . 8 8 6 6}$ & -0.1032 & -0.0858 & 0.2639 \\
Effects1 & 0.0685 & $\mathbf{0 . 6 0 6 1}$ & -0.0650 & 0.3233 & 0.3673 & 0.3011 & -0.2905 & -0.1619 & 0.0245 & 0.0940 & 0.1736 \\
\hline
\end{tabular}

Method: principal-component factors, Rotation: orthogonal varimax (Kaiser off), Number of observations $=101$, Retained factors $=10$.

this was based on the high factor loadings of the items; how restriction on land has changed community cohesion, response of community members in response to land demarcation, and means by which land is acquired. Factor three was labeled "Contribution of social organizations to the management of natural resources" and explained $9.5 \%$ of the variance. Factor four was labeled "Rationale for access to protected areas was" based on high factor loadings of the items; access to wetlands, reasons for access to forests, reasons for access to game reserves. This factor explained $8.6 \%$ of the variance. Factor five was labeled "Institutional changes that have occurred in the management of wetlands" and was based on high loadings of the items; changes in the management of wetlands, and reasons for access to wetlands. This factor explained $7.6 \%$ of the variance. Factor six was based on high factor loadings of the items; recommendations to improve utilization of the watershed, assessment of changes in gender roles were labeled "Interventions in utilization of wetlands" and explained $7.0 \%$ of the variance. Factor seven was labeled "Access to protected areas" and explained 6.7\%. Factor eight was labeled "Value of local institutions in the control of wetlands". Factor nine was labeled "Social effects of degradation of the wetlands" and was based on the high factor loadings of the variables; "social effects of degradation of wetlands on the communities" and factor ten was labeled "how use of the watershed has contributed to tribal conflicts" and was based on high factor loadings of the following variables; how the watershed contributes to tribal conflicts.

\subsection{Perception of Respondents on Socio-Cultural Interests Factors in Watershed Management}

Table 3 shows the perceptions of respondents on how social factor variables affect land use management within Awoja watershed.

Table 3 indicates the perceptions of the respondents on the different factors playing a role in the Awoja watershed management. From the analysis of the factors, cultural institutions were significant in reducing and settling land conflicts, restricting the sale of land. Clans were significant in dividing, demarcating 
Table 3. Perception of respondents on socio-cultural interest factors.

\begin{tabular}{|c|c|c|c|}
\hline Cultural influence on access to resources & Male & Female & Total \\
\hline Reduce and settle land conflicts & $7(5.8)$ & $6(10.0)$ & $13(7.2)$ \\
\hline Restrict the sale of land & $22(18.3)$ & $14(23.3)$ & $36(20.0)$ \\
\hline The clan divides, demarcates and allocates land to members & $48(40.0)$ & $18(30.0)$ & $66(36.7)$ \\
\hline $\begin{array}{l}\text { The clan has committees that oversee access and utilization of } \\
\text { land }\end{array}$ & $14(11.7)$ & $8(13.3)$ & $22(12.2)$ \\
\hline The clan owns and controls access to land & $10(8.3)$ & $6(10.0)$ & $16(8.9)$ \\
\hline Women are denied to own land by the clan & $19(15.8)$ & $8(13.3)$ & $27(15.0)$ \\
\hline \multicolumn{4}{|l|}{ Changes in social cohesion } \\
\hline Family members have conflicts on land & $35(29.4)$ & $22(37.9)$ & $57(32.2)$ \\
\hline Some family members have migrated & $37(31.1)$ & $16(27.6)$ & $53(29.9)$ \\
\hline New people have joined the family & $47(39.5)$ & $20(34.5)$ & $67(37.8)$ \\
\hline \multicolumn{4}{|l|}{ Social organizations to manage natural resources } \\
\hline Through co-funding to adaptation Projects & $11(9.5)$ & $3(5.2)$ & $14(8.1)$ \\
\hline Through provision of land for adaptation projects & $15(12.9)$ & $6(10.3)$ & $21(12.1)$ \\
\hline Through mobilization of community members & $90(77.6)$ & $49(84.5)$ & $139(79.9)$ \\
\hline \multicolumn{4}{|l|}{ Institutions changes in management of the watershed } \\
\hline New institutions have emerged & $21(18.3)$ & $11(19.3)$ & $32(18.6)$ \\
\hline Some institutions have changed their structures & $34(29.6)$ & $14(24.6)$ & $48(27.9)$ \\
\hline Some institutions have changed their mandates & $47(40.9)$ & $22(38.6)$ & $69(40.1)$ \\
\hline Institutions have become more responsive & $13(11.3)$ & $10(17.5)$ & $23(13.4)$ \\
\hline \multicolumn{4}{|l|}{ Interventions in utilization of wetlands } \\
\hline $\begin{array}{l}\text { Animal paddocking should be promote to regulate animals in } \\
\text { wetlands }\end{array}$ & $7(6.1)$ & $1(1.7)$ & $8(4.6)$ \\
\hline Avoid bush burning and promote the planting of tree & $5(4.3)$ & $13(21.7)$ & $18(10.3)$ \\
\hline Demarcating and gazette the wetlands & $7(6.1)$ & $6(10.0)$ & $13(7.4)$ \\
\hline Educating and sensitizing people on watershed management & $15(13.0)$ & $5(8.3)$ & $20(11.4)$ \\
\hline Formulation and enforcement of strict regulations & $2(1.7)$ & $0(0.0)$ & $2(1.1)$ \\
\hline Motivation and involvement of leaders & $6(5.2)$ & $3(5.0)$ & $9(5.1)$ \\
\hline Power of clan leaders should be reduced & $11(9.6)$ & $4(6.7)$ & $15(8.6)$ \\
\hline Promote family planning to control population increase & $17(14.8)$ & $7(11.7)$ & $24(13.7)$ \\
\hline Provide nearby water points/sources & $8(7.0)$ & $9(15.0)$ & $17(9.7)$ \\
\hline Women should be given and encouraged to share land & $37(32.2)$ & $12(20.0)$ & $49(28.0)$ \\
\hline
\end{tabular}

and allocating land to members, overseeing access and utilization of land. Respondents also perceived that social cohesion was an important factor in watershed management. They note that increasing trends of migrations, had reduced the social cohesion among close family members and had affected the local systems for land management that had been based on clan systems. They also 
noted that some family members had migrated and new people had joined the communities thereby creating a new order in the resource access.

The emergence of new social organizations for watershed management was perceived as quite important in the management of the watershed. They were significant in mobilizing co-funding to adaptation projects, provision of land for adaptation projects and mobilization of community members. It was noted that some institutions had changed their structure while other institutions have even changed their mandates. It was noted that many institutions have become more responsive to the emerging climate change adaptation needs.

Finally, new interventions for protection of watershed resources also led to changes in the norms related to community management of the watershed. For instance the introduction of paddocking to regulate animals in wetlands, rules against bush burning and promotion of tree planting, demarcation of grazing land, and gazetting the wetlands were some of the interventions that were alien to the normal community practice of watershed management. Other new nterventions include educating and sensitizing people on watershed management, formulation and enforcement of strict the community on regulations, motivation and involvement of leaders, promoting family planning to control population increase and providing accessible water points/sources.

\subsection{Relationships between Social Issues and Watershed Management}

The relationship between social issues was established using the Pearson product moment correlation coefficient. The results are presented in Table 4.

From the correlation results in Table 4, it can be observed that there is a significant relationship between the social issues and management of the watershed $(\mathrm{r}=0.353, \mathrm{P}<0.01)$. The results however, indicated a negative relationship between social issues and climate change factor. This means that as climate change effects increase, the efficacy of socio cultural institutions reduces. From the qualitative data it was found that the intensity of climate change deteriorates social cohesion, social structures and systems. For example, floods and the subsequent displacements affect the morals of the community members. In Magoro camp it

Table 4. Relationship between social issues, climate change and management of the watershed.

\begin{tabular}{ccccc}
\hline Variable & & $\mathbf{1}$ & $\mathbf{2}$ & $\mathbf{3}$ \\
\hline Watershed Management (1) & Pearson Correlation & 1.000 & & \\
& Significance (2-tails) & & & \\
Social Issues (2) & Pearson Correlation & 0.353 & 1.000 & \\
& Significance (2-tails) & $0.003^{* *}$ & & \multirow{2}{*}{ (2) } \\
Climate Change Factors (3) & Pearson Correlation & -0.098 & $-0.489^{* * *}$ & 1.000 \\
& Significance (2-tails) & 0.315 & 0.000 & \\
\hline
\end{tabular}

*** implies sig at $0.001,{ }^{* *}$ implies sig at $0.01,{ }^{*}$ implies sig at 0.05 . 
was mentioned that traditional leaders had lost their power and influence and could no longer implement the rules on conservation as they used to. It was reported in that there had been moral degeneration including prostitution and domestic violence in climate refugee camps or settlements. It was also reported of people staying with animals in the same houses due to lack of space and this had a likelihood of spreading animal diseases to people.

However, despite the negative correlation between climate change and social factor variables, the results showed that there was a positive correlation between social issues and watershed management, which implies that social organization was very important in land use management. It was noted for example that village committees were important in dissemination of information about climate change and adaptation alternatives, reflective circles within the communities were important in decision making on how to control degradation.

As can be observed in Table 4, the results indicated a level of significance of 0.000 an adjusted $R$. Square of 0.125 . The results therefore indicate that the overall relationship between social issues and management of the watershed was significant. The study also examined the social issues on factor by factor and the results are presented in Table 5.

In view the above results from Table 4 and Table 5; two emerging issues are evident: 1) Social factor variables (SS2, SS3, SS4, SS5 and SS6) present a significant correlation with the management of the watershed 2) Climate change has a negative correlation with social systems within the watershed thereby constraining sustainable natural resource management.

\subsection{Influence of Social Factor Variables on Watershed Management}

In order to ascertain the influence of each of the factors, a logistic regression model was used as indicated in Table 6.

Table 5. Relationship between social issues factors and watershed management.

\begin{tabular}{lcc}
\hline \multicolumn{1}{c}{ Social factors and management of the watershed } & $\mathrm{R}$ & Sig \\
\hline SS1-Cultural influences on access to land resources & -0.155 & 0.124 \\
SS2-Social cohesion & $0.273^{* *}$ & 0.006 \\
SS3-Contributions of social organizations & $0.417^{* * *}$ & 0.000 \\
SS4-Rationale for access to protected areas & $0.203^{*}$ & 0.038 \\
SS5-Community involvement & $0.560^{* * *}$ & 0.000 \\
SS6-Interventions in utilization of the watershed & $-0.249^{*}$ & 0.012 \\
SS7-Insitutional control of wetlands use & -0.004 & 0.969 \\
SS8-Social effects of degradation of the watershed & -0.112 & 0.267 \\
SS9-Tribal conflicts in the use of the watershed & 0.126 & 0.213 \\
\hline
\end{tabular}

Factors obtained after data reduction, factor analysis factor loadings. ${ }^{* *}$ implies sig at $0.001,{ }^{* *}$ implies sig at $0.01,{ }^{*}$ implies sig at 0.05 . 
Table 6. The logistic regression results of the social issues and watershed management.

\begin{tabular}{cccccc}
\hline SS1 & $\mathbf{0 . 6 1 3 4 6 4 1}$ & $\mathbf{0 . 3 1 9 4 0 4 8}$ & $\mathbf{0 . 3 4 8}$ & $\mathbf{0 . 2 2 1 1 0 8 1}$ & $\mathbf{1 . 7 0 2 0 5 6}$ \\
SS2 & $\mathbf{0 . 2 3 2 9 6 3 2}$ & $\mathbf{0 . 1 1 6 8 2 4 5}$ & $\mathbf{0 . 0 0 4}$ & $\mathbf{0 . 0 8 7 1 8 3 4}$ & $\mathbf{0 . 6 2 2 5 0 2 3}$ \\
SS3 & 0.47719 & 0.2179806 & 0.105 & 0.1949226 & 1.168209 \\
SS4 & 1.162332 & 0.6149481 & 0.776 & 0.4120878 & 3.278463 \\
SS5 & 0.7726319 & 0.4598687 & 0.665 & 0.2406243 & 2.48088 \\
SS6 & 0.4856264 & 0.2033118 & 0.084 & 0.2137663 & 1.103228 \\
SS7 & $\mathbf{2 . 5 6 2 0 3 4}$ & $\mathbf{1 . 0 8 9 9 0 7}$ & $\mathbf{0 . 0 2 7}$ & $\mathbf{1 . 1 1 2 9 5 6}$ & $\mathbf{5 . 8 9 7 8 2 5}$ \\
SS8 & 0.6974949 & 0.2124144 & 0.237 & 0.3839873 & 1.266966 \\
SS9 & $\mathbf{0 . 2 9 8 6 1 7 8}$ & $\mathbf{0 . 1 0 6 8 9 0 5}$ & $\mathbf{0 . 0 0 1}$ & $\mathbf{0 . 1 4 8 0 5 6 5}$ & $\mathbf{0 . 6 0 2 2 8 7 8}$ \\
\hline
\end{tabular}

Key: SS1-Cultural influences on access to land resources, SS2-Social cohesion, SS3-Contributions of social organizations to the management of natural resources in the watershed, SS4-Rationale for access to protected areas, SS5-Community involvement, SS6-Interventions in utilization of the watershed resources, SS7-Insitutional control of resource use, SS8-Social effects of degradation of the watershed, SS9-Tribal conflicts in the use of the watershed.

As can be observed in Table 6, there were a number of factors that had an increasing influence on watershed management while others had a decreasing influence. Those with an increasing influence were SS4-Rationale for access to protected areas and SS7-insitutional control of wetlands use, where the Odds Ratio was greater than 1 . However, while the influence SS7 was increasing and significant, the influence of SS4-Rationale for access to protected areas was increasing but not significant.

Table 6 also shows that factor SS2-Family cohesion and SS9-Tribal conflicts in the use of the watershed had a decreasing influence on watershed management. This means that, the stronger the family cohesion, the lower was its contribution to watershed management. This finding depicts the negative contribution family cohesion has on control of access to protected resources. The stronger was the family cohesion, the more likely they were able to resist conservation measures that infringe on their ownership rights.

The detailed analysis of the above findings was categorized into various thematic areas to streamline presentation of both descriptive and qualitative data generated by the study as presented below.

\subsubsection{Factors with Increasing Influence on Management of Watershed Resources}

From Table 6, two factors; SS7-insitutional control of wetlands use had increasing and significant influence on resource management in the watershed. This signifies the role of formal institutions in controlling wetlands use and the power of state institutions in the developing and implementing watershed management decisions.

1) Institutional control of resource use

Respondents perceive local institution is an important driver in the sustainable watershed management. The findings indicate that many NGOs had changed their mandates to address the issues of climate change and had integrated good so- 
cial norms for watershed management into their practices. During the face-to-face interaction with the respondents, it was revealed that NGOs had formed Village Committees who regularly reviewed environmental and climate change issues in village meetings called "reflective circles". These had played a significant role in improving land use management in the watershed.

Respondents noted increased interventions by NGOs and government at the level of conservation policies aimed at reducing the negative effects of climate change. It was mentioned for example, that food storage systems were being promoted and established by government agencies as well as NGOs. The government and other climate change agencies were encouraging agricultural extension agencies to assist the households in using the right chemicals to control postharvest pests and diseases. Cooperative societies who buy produce at the time of harvest and be able to sell them to the households when the harvest reduces but at affordable prices, were being promoted.

Another contribution of management institutions to improved watershed management was the increasing involvement of women groups in village committees. Women groups were perceived by respondents to be more active in conservation activities than the men. It was also reported that Village Committees established by a climate change consortium composed of all climate change NGOs in Katakwi was very significant in the watershed management. It was reported that these committees were very effective in resolving conflicts, identifying those who violate environmental regulations and at times they hold their own prosecution meetings where fines are placed on those who violate the rules. It was noted that these efforts had even become more effective than that of the local government agencies because the village committees were more trusted by the local people.

\section{2) Cultural influences in watershed management}

Respondents perceive that clan leaders play a central positive role in controlling access to watershed resources. It was mentioned that community members respected the clan leaders more than the local government leaders. It was revealed that it was common for the people to report their complaints to the clan leaders than to the local government leaders. In Angisa, Katakwi District it was reported that even the local government leaders in the area were reporting their complaints to the clan leaders other than to the government leadership. This made a community member wonder how one would report to the local leaders when he knows the lead himself will go to the traditional leader when he has a problem. They revealed that the local government system was only important when the community members needed services provided by the government such as National ID, health, education, Operation Wealth Creation seedlings and other services but not for other problems within the community.

\subsubsection{Factors with Decreasing Influence on Sustainable Watershed Management}

The interaction among climate change variable with social factor variable was 
analyzed. The main aim was to determine the effect of climate change on socio cultural institutions. This would provide a clue about how social institutions operate in a changing climate. From the correlation results in Table 4, climate change effects had negative relationships with both the social factor variables as well as with management of the watershed: Extreme climate change factors appear to erode the effectiveness of the social institutions that are so crucial in the management of the watershed. The analysis of the effects of climate change on non-formal social institutions is presented below.

From Table 6 other than factor SS2 and SS7, all other factors namely SS1Cultural influences on access to land resources, SS3-contributions of social organizations to the management of natural resources in the watershed, SS5-Role of community involvement, SS6-Interventions in utilization of the watershed, SS8-social effects of degradation of the watershed, SS9-Tribal conflicts in the use of the watershed; all had a decreasing influence on watershed management..

An analysis of views from respondents indicated that as climate change effects intensify, the traditional regulations and norms tend to crumble. Traditional leaders are no longer capable of implementing the regulations on environmental protection during extreme climate events because they suffer the same effects of climate change as their subjects. Some of the major indicators of the negative effects of climate on the social institutions are analyzed below.

1) Climate, conflicts and weakening of social institutions

From Table 6, factor SS9-Tribal conflicts in the use of the watershed was found to have a significant decreasing influence on watershed management $(\mathrm{r}=$ $0.2986178, \mathrm{P}<0.01)$. Respondents perceived that extreme climate events make control of access to resources very difficult. It was revealed in the interviews that during extreme draughts, the watershed becomes so open that at times it was not easy to control movements across boundaries. It was possible for the people of Soroti to grazetheir livestock and sometimes find they are already in Amuria and the situation was the same for Amuria and Katakwi. This has enabled many people from other districts to find their ways into the watershed. This generates a lot of conflicts with the indigenous communities.

Other conflict associated with migration was the challenge of theft of animals amongst the tribes and this was found prevalent between Katakwi people and the Karamajong. It was also revealed that there were conflicts on the use of water sources especially Lakes Opeta and Lake Bisina. The two lakes border different Districts and this has become a source of conflict because different fishermen of different districts also claim ownership to these resources making it very difficult to police. This conflict has been around for along time and at times had become violent.

Other climate related conflict that was more pronounced was the ambiguity of resource boundaries across tribal territories particularly between the Iteso and the Karamojong. Consequently, tribal fights overgrazing land, leadership, and struggle for resources in the watershed, and conflict over land for cultivation has 
been common particularly during extreme draughts.

The results hence indicate the link between climate, conflicts and the functioning of rural institutions. Respondents perceived that extreme climate events appear to fuel resource use conflicts while weakening the governance structures used in the implementation of environmental rules and regulations.

\section{2) Climate, social cohesion and watershed management}

Table 6 showed that social cohesion had a decreasing influence on watershed management $(r=0.2329632, \mathrm{P}<0.01)$. This means that the more the decline in social cohesion, the lower is its contribution to sustainable management of watershed resources. The study found that extreme climate events particularly floods caused social disintegration leading to the emergence of climate change refugees who move to camps located on high grounds at sub county level or school and church premises. It was mentioned by Key Informants in Katakwi that these camps are often not well managed by local authorities. Respondents mentioned increasing social degeneration in the camps. People in the camps no longer listen to their traditional leaders about environmental protection. Community members have stopped respecting their leaders because they find themselves suffering together with their leaders in the camps. Consequently some displaced traditional leaders have abandoned their people in the camps. An example, was given in Angisa Community in Katakwi where leaders had moved away to Magoro or Katakwi Town. Other social vices that have emerged include prostitution, drunkenness and lawlessness. All these have made the communities less concerned on environmental protection and more focused on using the resources for their own survival.

The study further examined the people's experience with sharing resources, a proxy for social cohesion. Respondents mentioned the decline in sharing of resources not only among the families but also with the other clans and tribes. Environmental officers in Katakwi and Amuria mention that where the Karamojong and Iteso were co existing and sharing land and food amicably such as in Apeitolim, they were very responsive to environmental programs such as tree planting and protection of water points.

There have been new trends in which immigrants negotiate with the indigenous people how to use the resources such as land and water with the locals. It was mentioned that the cattle keepers from Karamoja have negotiated with the people in Soroti and Katakwi how to co-exist and use the available pasture and water for their animals. It was revealed that the communities have accepted to co-exist so long as the immigrants are ready to behave as required by the locals. This has enabled the immigrants to access health facilities, school, and water sources among other resources in the area. It was also revealed however that some immigrants pay for the resources. It was revealed for example that if they want to cultivate on the land, they must negotiate aprice with the owner. This has happened many times and has aided co-existence of immigrants and the locals. Other experiences with sharing resources included the views that the immigrants negotiated with the help of the local leaders but at times, conflicts in- 
volving the immigrants and the locals have emerged and this has always affected harmony among locals and immigrants.

3) Cultural influences on watershed management

Community involvement in watershed management had a strong and significant correlation with watershed management as shown in Table 4. However, the Logistic Regression Model in Table 6 shows that the influence of community involvement to watershed management had a declining trend as shown by the odds ratio $(\mathrm{r}=0.7726319, \mathrm{P}<0.01)$. The results from the key informants interviews show how cultural systems resist government interventions aimed at environment protection. In Katakwi District for example the population was against any interventions by government involving land use for fear of land grabbing and land give away to investors. People argued that land for their ancestors could not be given away to anybody. This depicts the unsupportive role of clan structures to government interventions on land use. The clan structures were also reported to have defeated government promotion of land surveying in Soroti district that was meant to streamline land ownership and pave way for implementation of environmental protection measures. The government had encouraged the people to have their land surveyed and secure land titles but the community had refused thinking that the government was using this as a strategy to take over their land. Thus most interventions for environment conservation in Katakwi suffered the same fate due to this negative perception.

\section{4) Changes in gendered access to resources}

The study established that while the traditional male dominance to resource access was evident women were increasingly accessing some resources as well and vice versa. These changes were being precipitated by extreme climate events.

For example an examination on access to forests and woodlands indicated that the men had more access than the women although the access by women had increased compared to the last 10 years. Up to 86 (47.8\%) of respondents indicated men were accessing the forests and woodlands while women access by women were $58(32.2 \%)$ and the youth access was mentioned by $31(7.2 \%)$. The respondents indicated that forests were accessed mainly for charcoal burning. It was also revealed that while men were the main groups in charcoal burning women had started reversing this norm and were beginning to get involved in charcoal burning as well. The women explained that charcoal burning was the only remaining activity left for women to generate money for food, school fees and other social needs following displacement of rice growers from the wetlands due to demarcation of the wetlands.

The other reason for accessing the forests was said to be the collection of firewood. It was found that while the responsibility of collecting firewood was mainly for the women the men were getting involved in collecting firewood as well. However, while women collected firewood for home use men were cutting trees for sale to charcoal burners, brick makers, schools and hospitals. This commoditization of firewood by men is having negative environmental and social effects as the trees have gotten depleted. Consequently the women have had 
to put aside part of their core responsibility of cultivation and roam the woodlands looking for firewood. It was revealed by one woman in Omugenya that the women must now spare at least one day in the week to collect firewood.

An investigation on access to wetlands showed that the majority $129(71.7 \%)$ of the men had more access than the women and the youth. Up to 39 (21.7\%) said women were accessing the wetlands while the youth was mentioned by 4 (2.2\%) of the respondents. The youth were accessing the wetlands mainly for bird hunting and fishing as well. It was actually revealed by residents in Omugenya that there was increased bird hunting yet Awoja is a Ramsar site with some of the most rare bird species in the world. The extent of bird hunting threatens to extinct some bird species. The birds were mainly hunted for food and for sale to other members of the communities.

Hunting for wild animals was also indicated as another reason for accessing the forests and this was revealed to be the responsibility of the youth and some men. It was revealed that the wild meat was later sold in markets and restaurants within the villages. It should be noted however that all these activities were prohibited but the community members were doing them because there was poor enforcement of the laws. Some chairpersons revealed that the enforcement officials were not facilitated enough to monitor the use of such resources. It was also revealed that such activities had contributed to degradation of the watershed because in some areas, the forest cover had been almost completely removed.

During the interviews with community members, it was revealed that despite restrictions on sand mining by the local government, the men always collected sand for sale. A community member revealed that the men were collecting the sand on bicycles until they made substantial quantities for sale. All these had implications on the management of the watershed because collecting sand on bicycles looked so insignificant and not easily noticed but sand mining is degrading the wetlands and compromising their functions.

An investigation of access to wetlands and still showed the majority 129 (71.7\%) indicating that the men had more access than the women and the youth. Women access was represented by 39 (21.7\%) while the youth accessing the wetlands were $4(2.2 \%)$. During the interviews with community members in Amuria for, it was revealed that after the demarcation, the wetland was left for cattle keepers and this was generally a responsibility for the men. Women mainly access wetlands for cutting grass to thatch the houses, materials for crafts like mats, baskets and others. It was also revealed that women also accessed the wetlands for rice cultivation but this had reduced because of soil deterioration that cannot support rice cultivation anymore. The main reason remaining for women accessing the wetland was for fishing and even by moving through Awoja wetland in Omugenya, one would see women trying to dam the swamp in order to trap the fish. For the case of sand mines, it was revealed that it was mainly the men $140(77.8 \%)$ and the youth $28(15.6 \%)$ who had access while access by the women was indicated by only $1(0.6 \%)$.

From the above analysis it can be inferred that changes in access to wood- 
lands, wetlands and protected Ramsar sites threaten the social and ecological sustainability of the watershed. It should be noted that all these activities had implications on the management of the wetlands because the enforcement officers had become complacent thereby legitimizing the practices and making them look like new norms in the fight against economic hardships brought about by climate change. This finding relates closely with those of other scholars who have analyzed social issues in ecological systems and how they affect the management of watersheds. Participation of actors becomes an avenue for influencing practice and organizational change, as organizations are not stable and fixed objects, but rather something dynamic and performed, provisional and emerge through social practices 25 . Social practices evolve, taking on new forms over time and that regulation of social codes of conduct and shared cognitions and logics legitimize various types of collective action be them good or bad 26 .

\section{5) Changes in gender workloads}

The majority of the respondents 39 (22\%) revealed that women nowadays had more workload and responsibilities than in the recent past. The women were doing much more work compared to the men. Other than preparing the food the women were predominantly working in gardens, building houses and others are involved in other activities that were predominantly for the men.

During the interviews women revealed that the men spent most of the time drinking and dating other women and were not bothered about the status of their families. It was also revealed by some women that they were being forced to thatch the houses because they are the ones who feel the pressure of leaking houses more than the men who were most times already so drunk that they did not feel the impact of the leaking roofs.

The other changes in the gender roles included; women riding Bodaboda taxi bicycles which were unusual in the past. It was also revealed that women were engaged in thatching houses which should have been a responsibility of men this and was revealed by 33 (18\%). During the interviews women revealed that the men spent most of the time outside the home. By the time they came back home it would be late for the women to complain about the family. It was also revealed by some women that some men would already be too drunk to listen.

The practice of women getting engaged in illegal fishing and the entry of women in charcoal burning, sale of firewood and commercial fishing as well as illegal fishing activities threaten sustainable management of watershed resources. It can be noted that the changes in gender roles have mainly affected the women compared to the men. Men were only carrying out "software activities" such as planning, attending village meetings, participating in community services. Gender differences in the perception and adoption of strategies to cope and adapt to climate change impacts and other concomitant drivers. However, they also disentangle how different dimensions of identity such as caste, wealth and age intersect with gender shaping the interactions between farmers and ecosystems. 


\subsubsection{Summary of Findings on the Influence of Social Interest Factors}

The chapter unraveled the relationship between social factors and watershed management in a changing climate. As can be seen from Figure 1, and true to the proposition, social factor variables such as social cohesion, institutional control of access to resources and tribal conflicts had significant influence on watershed management. However the study also found that climate change had both positive and negative consequences on existing social institutions. It was also found that climate change had a negative relationship with watershed management largely due to its ability to intensify resource conflicts.

\section{Conclusions and Recommendations}

It can be concluded that in a changing climate, social institutions have both facilitating and constraining roles in natural resource management. Climate change appeared to have had a transformative effect on some institutions. For example, while clan leaders retained their control and ownership over land, the same institutions became weakened and disabled to implement norms on environment conservations during extreme events such as floods and extreme draughts. The clan systems were still recognized in resource management within the watershed but new issues continued to evolve that tended to weaken their roles in land use management.

It can also be conluded that the neglect of watershed management by the local government institutions contributes to uncontrolled access to watershed resources. Local government officials continue to exist alongside the local government and decentralized resource governance framework and continue to influence management of resources in a number of forms. It was found that local government officials continue to attribute responsibility of resource management to traditional

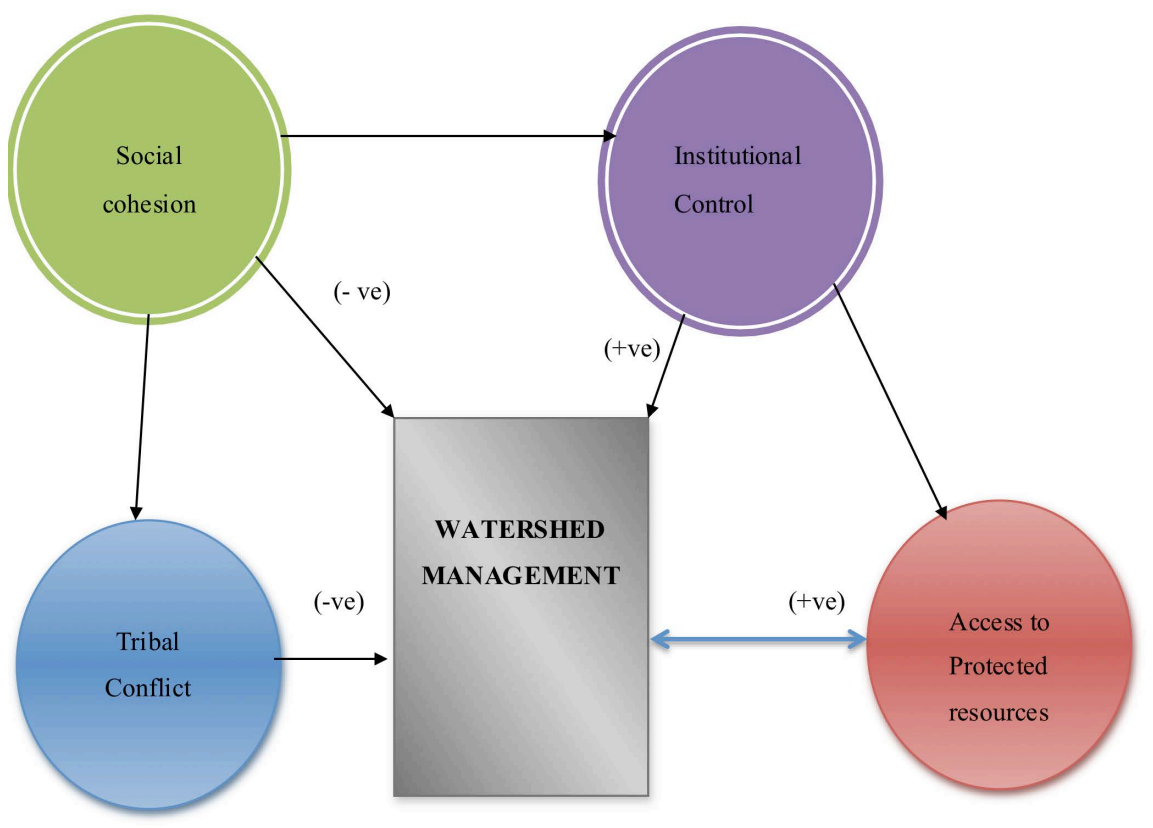

Figure 1. The influence of social interest factors and watershed management. 
leadership and this has reduced credibility of the local government leadership in watershed management and has uplifted the local leadership yet the traditional leadership is no longer as strict as it has always been. These trends contribute to ineffective watershed management.

The final conclusion is that there is a tension between the emerging social transformations arising from climate change adaptation needs and the local government rules and regulations. The traditional leadership managed by the clan heads, used to be strong but has been weakened by emerging regulations. It can be observed that despite the compromises and negotiations mounted by the community members, the public law in some circumstances still takes an upper hand because of the coercive power of the state. This was witnessed in Amuria where even when the locals did not want demarcation of the wetlands to take place arguing that the wetlands were their cultural heritage, the state power was so strong that demarcation had to take place. This however did not entirely mean that the communities had taken all changes lying down, the clan and community leaders were able to negotiate many compromises including the buffer zone to the wetlands, which was reduced to 15 meters from 30 meters to the swamp. Social capital in weaker communities was not capable of influencing decisions effectively. For example in Angisa it was found that the social fabric was weaker due to their weak links with local government in Katakwi and the central government in Kampala. Thus, despite the many negotiations they have tried to engage government into, the community members still lost their land and were pushed to the wetland in favor of wild life.

From the findings of the study, it is recommended that resource governance systems need to strengthen the role of social institutions in the management of watershed resources in Awoja. This is important because cultural institutions were found to be very significant in complementing the decentralized frameworks in controlling access and use of resources in the watershed. The cultural leadersip needs to be involved in the formulation of policies and other decisions associated with control of access and use of resources in the watershed. Any interventions in climate change management should therefore take cognition of the fact that climate change has both positive and negative consequences on existing social institutions. There is need to ensure that new adaptation interventions involve the participation of existing local institutions while at the same time monitoring the emergence of negative social cultural norms that may hinder effective and sustainable environmental management.

\section{Conflicts of Interest}

The authors declare no conflicts of interest regarding the publication of this paper.

\section{References}

[1] Agrawal, A. and Perrin, N. (2009) Climate Adaptation, Local Institutions and Rural Livelihoods. In: Adger, W.N., Lorenzoni, I. and O’Brien, K., Eds., Adapting to Cli- 
mate Change: Thresholds, Values, Governance, Cambridge University Press, Cambridge, 1 .

[2] McCarthy, M.A., Possingham, H.P., Day, R.J. and Tyre, J.A. (2001) Testing the Accuracy of Population Analysis. National Center for Ecological Analysis and Synthesis, University of California, Santa Barbara. https://doi.org/10.1046/j.1523-1739.2001.0150041030.x

[3] Swart, R., Martin, L., Parry, N., Smit, B., Pilifosova, O., Burton, I. and Challenger, B. (2013) Climate Change and Sustainable Development. National Institute for Public Health and the Environment, IPCC Working Group III, RIVM, Bilthoven.

[4] Anderson, K. and Kaizer, F. (2011) The Challenge of Common-Pool Resources Environment. Journal of Natural Resource Policy and Sustainable Development, 50, 127.

[5] Paulson, S., Gezon, L.L. and Watts, M.J. (2003) Locating the Political in Political Ecology: An Introduction. Human Organization, 62, 205-217. https://doi.org/10.17730/humo.62.3.e5xcjnd6y8v09n6b

[6] Carlsson, L. and Berkes, F. (2005) Co-Management: Concepts and Methodological Implications. Journal of Environmental Management, 75, 65-76.

https://doi.org/10.1016/j.jenvman.2004.11.008

[7] Kunihira, R. (2014) Socio-Cultural Factors Affecting Women's Participation in Watershed Resources Management in Chahi Catchment, South-Western Uganda. MSc Thesis, Integrated Watershed Management in the School of Pure and Applied Sciences of Kenyatta University, Nairobi, 124 p.

[8] World Bank (2013) Development of the Awoja Catchment Management Plan in the Kyoga Water Management. Zone Contract: 7164726. Final Stakeholder Engagement Report.

[9] Mbogga, M. and Malesu De, L.J. (2014) Trees and Watershed Management in Karamoja, Uganda. Department for International Development, London, 4, 25. https://doi.org/10.12774/eod_hd.december2014.mboggametal

[10] Amin, M.E. (2005) Social Science Research: Conception Methodology and Analysis. Makerere University Printeryafd, Kampala.

[11] Mugende, O.M. and Mugenda, A.G.M. (1999) Research Methods. African Center for Technology Studies Press, Nairobi.

[12] Tabachnick, B.G. and Fidell, L.S. (2001) Using Multivariate Statistics. 4th Edition, Allyn and Bacon, Boston.

[13] Sharma, S. (1996) Applied Multivariate Techniques. John Wiley and Sons Inc., New York, 512 p. 